\title{
DETERMINATION OF AMBROXOL IN SYRUPS USING DIFFUSE REFLECTANCE SPECTROSCOPY
}

\author{
José L. Rufino*, Joel M. Santos, Mayra A. Rodrigues, Helena R. Pezza e Leonardo Pezza
}

Instituto de Química, Universidade Estadual Paulista, CP 355, 14801-970 Araraquara - SP, Brasil

Recebido em 6/8/08; aceito em 19/1/09; publicado na web em 3/7/09

\begin{abstract}
This paper reports an analytical method for the determination of ambroxol in micellar medium by spot test-diffuse reflectance spectroscopy. The reflectance measurements were performed analyzing the colored compound $(\lambda=520 \mathrm{~nm})$ produced from the reaction between ambroxol and $p$-dimethylaminocinnamaldehyde on the surface filter paper. The linear range was from $1.21 \times 10^{-3}$ to $9.65 \times 10^{-3} \mathrm{~mol} \mathrm{~L}^{-1}\left(500-4000 \mu \mathrm{g} \mathrm{mL}^{-1}\right)$. The limit of detection and quantification were $3.50 \times 10^{-4} \mathrm{~mol} \mathrm{~L}^{-1}\left(145 \mu \mathrm{g} \mathrm{mL} \mathrm{mL}^{-1}\right)$ and 1.16 x $10^{-3} \mathrm{~mol} \mathrm{~L}^{-1}\left(481 \mu \mathrm{g} \mathrm{mL}^{-1}\right)$, respectively. Five commercial samples were analysed and the results obtained by the proposed method were in good agreement with those obtained by the literature method at $95 \%$ confidence level.
\end{abstract}

Keywords: ambroxol; diffuse reflectance spectroscopy; -dimethylaminocinnamaldehyde.

\section{INTRODUCTION}

Ambroxol, trans-4-(2-amino-3,5-dibromobenzylamino) cyclohexanol hydrochloride (Figure 1), is a compound with potent mucolytic activity that is used as an expectorant and bronchosecretolytic in therapeutics. ${ }^{1-3}$ Ambroxol stimulates the transportation of viscous secretion in the respiratory organs and reduces secretion stagnation. It is administered as hydrochloride in daily doses of 30-120 mg and is available commercially as syrups, granules, tablets, or in solutions, utilized in the injectable form or for inhalation.,

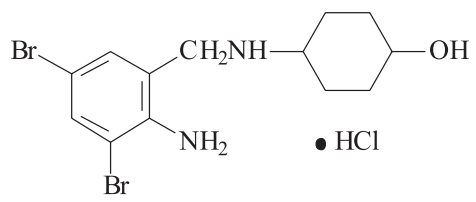

Figure 1. Chemical structure of ambroxol hydrochloride

Several different methods have been used for the determination of ambroxol hydrochloride in pharmaceutical preparations including LC-MS,${ }^{6}$ spectrophotometry, ${ }^{7}$ HPLC,${ }^{8-10}$ flow injection analysis, ${ }^{11,12}$ capillary electrophoresis and isotachophoresis. ${ }^{13,14}$

However, as far we know, there is no any reflectometric method for the determination of ambroxol related in the literature. Recently were reported reflectometric methods for the determination of acetylsalicylic acid ${ }^{15}$ and furosemide ${ }^{16}$ in pharmaceutical preparations. Despite the fact that analytical reflectometric methods in the visible region of the spectrum are not very common, some have been recently published. ${ }^{17-24}$

The diffuse reflectance methods present some advantages, such as simplicity and extremely low consumption of reagents. Moreover, the reflectance measurements can be performed in locus using a very simple homemade reflectometer or a portable diffuse reflectance spectrophotometer, which are small, lightweight, inexpensive and battery operated, characteristics highly attractive to facilitate analysis at the location of the system under investigation. Thus, the development of a more rapid, portable and simple method with low consumption of reagents/solvents, such as the diffuse reflectance spectroscopy using spot test, is an attractive alternative for detection of ambroxol in pharmaceuticals.

*e-mail: rufino@iq.unesp.br
The present paper reports a rapid and accurate reflectometric method for the determination of ambroxol hydrochloride in the syrups formulations. The performance of the developed method was validated in terms of selectivity, linearity, precision and accuracy.

\section{EXPERIMENTAL}

\begin{abstract}
Apparatus
The reflectance measurements were collected using a hand-held integrating sphere (ISP-REF, Ocean Optics, Dunedin, USA) connected to a fiber optic spectrometer miniature (USB4000, Ocean Optics) with a CCD array detector. Software SpectraSuite (Ocean Optics) was used for acquisition and storage of spectra. Eppendorf (10 to $100 \mu \mathrm{L}$ ) and Brand (100 to $1000 \mu \mathrm{L}$ ) micropipettes were used to measure smaller volumes in the experiment.
\end{abstract}

\section{Materials, chemicals and solutions}

Whatman 41 filter paper was used as solid support. The excipients used in the interference study were of pharmaceutical grade. A solvent used was methanol (analytical reagent grade) from Mallinckrodt, Xalostoc, Mexico. $p$-Dimethylaminocinnamaldehyde ( $p$-DAC) (Riedel-de haën, Germany) was used to prepare a $0.70 \%$ $\mathrm{m} / \mathrm{v}$ in methanol. The solutions of $\mathrm{HCl}$ were prepared in methanol. Stock solution of sodium dodecil sulfate (SDS) (Sigma, St. Louis, USA) a $1.0 \times 10^{-1} \mathrm{~mol} \mathrm{~L}^{-1}$ was prepared in deionized water. Standard ambroxol was purchased from Purifarma (São Paulo, Brazil, purity $99.7 \%$ ) and standard solutions were daily prepared as $7.24 \times 10^{-2} \mathrm{~mol}$ $\mathrm{L}^{-1}$ in methanol. Working standard solutions in the range $1.21 \times 10^{-3}$ to $9.65 \times 10^{-3} \mathrm{~mol} \mathrm{~L}^{-1}$ were prepared by appropriate dilution of the standard solution in methanol with $3.0 \times 10^{-2} \mathrm{~mol} \mathrm{~L}^{-1}$ of SDS.

\section{Optimization of variables}

The variables were optimized by full-factorial design and response surface methodology. 25

A full-factorial design $2^{3}$ was carried out to distinguish the significant parameters. The result of this design was used to plan a subsequent design having a central composite to obtain the response surface. All statistical calculations were performed using Statistic 6.0 software. 


\section{Samples preparation}

Five commercial samples of pharmaceutical formulations (syrups) containing $30 \mathrm{mg} / 5 \mathrm{~mL}$ or $15 \mathrm{mg} / 5 \mathrm{~mL}$ of ambroxol hydrochloride from different batches and different brands were purchased in local drugstores in Araraquara city, (Brazil) and analysed by the proposed method.

An aliquot of this solutions equivalent to approximately $6.0 \mathrm{mg}$ of drug was transferred to a $5.0 \mathrm{~mL}$ volumetric flask. In the sequence, $1.5 \mathrm{~mL}$ of SDS $\left(1.0 \times 10^{-1} \mathrm{~mol} \mathrm{~L}^{-1}\right)$ was added and the volume completed with methanol.

\section{Procedure of spot test reaction}

The solutions were spotted onto the filter paper (Whatman 41) of the $2.25 \mathrm{~cm}^{2}$ using a micropipette fixed in a holder according to procedure described by Tubino et al. ${ }^{26}$ To carry out measurements, first $30 \mu \mathrm{L}$ of the $\mathrm{HCl}$ solution was spotted followed by addition of 20 $\mu \mathrm{L}$ of the samples solution and $30 \mu \mathrm{L}$ of the reagent solution. In the sequence, the reflectance measurements of the purple color product were carried out at $520 \mathrm{~nm}$ at room temperature. Blank with $30 \mu \mathrm{L}$ of $\mathrm{HCl}$ solution, $20 \mu \mathrm{L}$ SDS solutions $\left(3.0 \times 10^{-2} \mathrm{~mol} \mathrm{~L}^{-1}\right)$ in methanol and $30 \mu \mathrm{L}$ of reagent solution was used as reference.

In order to evaluate the optical stability of the product of spot test reaction between ambroxol and $p$-DAC on filter paper, a kinetic monitoring of the $A_{R}$ values at $520 \mathrm{~nm}$ was carried out. The obtained results demonstrated that the product is stable for at least $50 \mathrm{~min}$, at room temperature $\left(25^{\circ} \mathrm{C}\right)$.

\section{RESULTS AND DISCUSSION}

Ambroxol (Scheme 1) is an aromatic primary amine, which can react with $p$-DAC in acid medium. The reaction between aromatic amines and $p$-DAC is assumed to take place via the condensation of the protonated primary amino group with the carbonyl group of the reagent to produce an imminium salt. ${ }^{16,27,28}$ The probable mechanism for this reaction is shown in Scheme 1, which is based on reactions suggested in the literature. ${ }^{16,27,28}$

It is known that micellar media formed by surface-active substances are capable of essentially changing the equilibrium, kinetic and spectral properties of reactions in which they are involved, and this has been used to improve the characteristics of analytical procedures. ${ }^{29}$ The effect of surfactant micelles in the condensation of aldehydes, such as $p$-DAC, with amines has been subject of a number of publications. ${ }^{30-32}$

Preliminary experiments revealed a significant enhancement of magnitude in the sensitivity of the reaction in the presence of SDS and no shift in the absorption maximum takes place. In the sequence, was evaluated the stability of colored product and observed that the reflectance measurement remained stable at least $24 \mathrm{~h}$ at room temperature $\left(25^{\circ} \mathrm{C}\right)$.

\section{Optimization of variables}

The optimization was developed by experimental design, including two kinds of designs: the factorial design to evaluate which of the variables were significant factors and the central composite design, to obtain the response surface from which the optimal factors that give a maximum response can be deduced.

According to Wendlant and Hecht ${ }^{33}$ the color of the spot test should be uniform over the entire surface in order to ensure reproducible reflectance measurements. Presuming the spot test reaction can be affected by multiple factors, the most favorable conditions for the reaction were investigated, including the addition order of reagents.

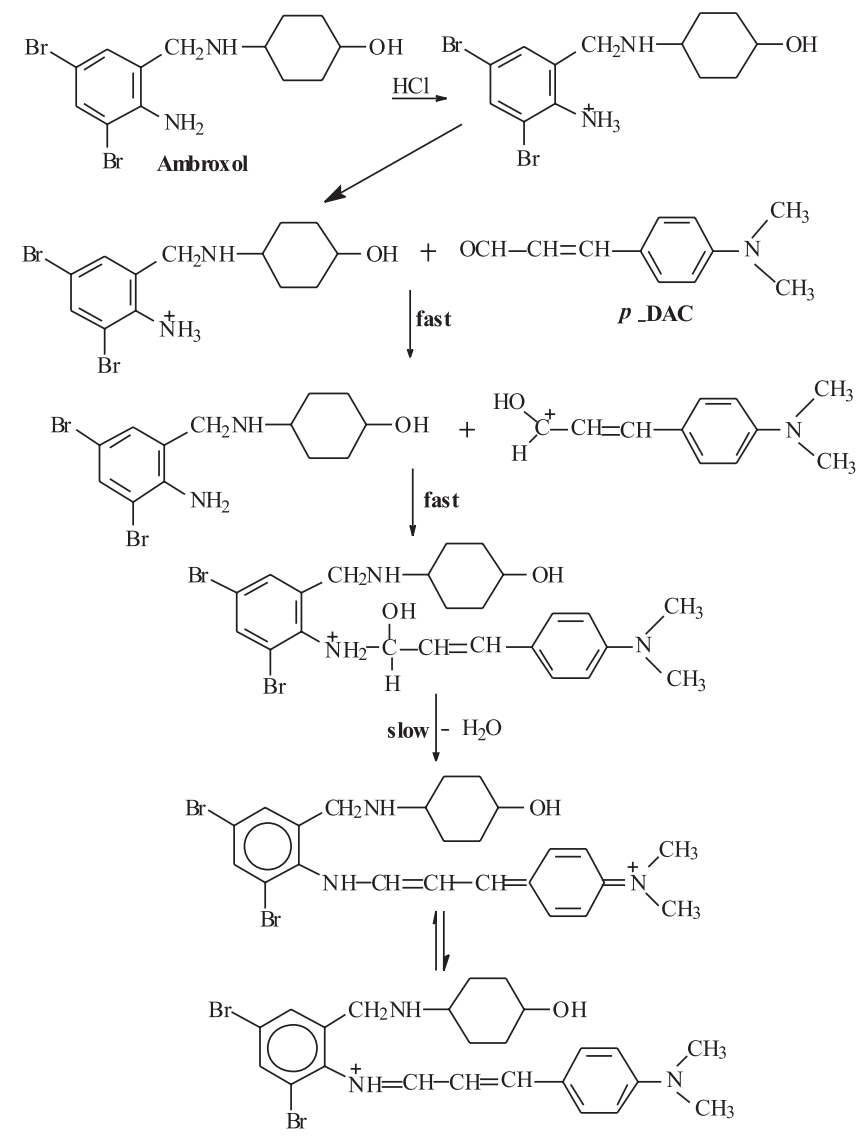

Im mminium salt

Scheme 1. Proposed mechanism of the reaction between ambroxol and pDAC in medium acid

Previous assays performed in our laboratory showed that on the filter paper surface better spots were obtained under the following addition order: $\mathrm{HCl}$ solution followed by addition of the samples solution and reagent solution.

In the sequence, a $2^{3}$ full-factorial design was carried out, which allowed simultaneously studying three variables that could have an important effect on the reflectance signal. In this design, the variables were studied at two levels: low (-1) and high $(+1)$. The variables of interest were $\mathrm{SDS}, \mathrm{HCl}$ and $p$-DAC concentrations.

For this design, 8 experiments were necessary, which were realized in triplicate and randomized to eliminate any environmental variation. The variables and their levels are summarized in Table 1. The highest and lowest values of each variable were defined based on preliminary experiments. The concentration of ambroxol was kept constant at $2.41 \times 10^{-3} \mathrm{~mol} \mathrm{~L}^{-1}$.

Table 1. Variables studied and values of the levels

\begin{tabular}{lcc}
\hline Variables & Low level (-1) & High level (+1) \\
\hline$[\mathrm{HCl}] \mathrm{mol} \mathrm{L}^{-1}$ & 0.50 & 1.00 \\
{$[p-\mathrm{DAC}] \% \mathrm{~m} / \mathrm{v}$} & 0.40 & 0.80 \\
{$[\mathrm{SDS}] \mathrm{mol} \mathrm{L}$} & \\
\hline
\end{tabular}

As result of the full factorial design, Pareto chart was drawn (Figure 2) in order to visualize the estimated effects of the main variables and their interactions. 


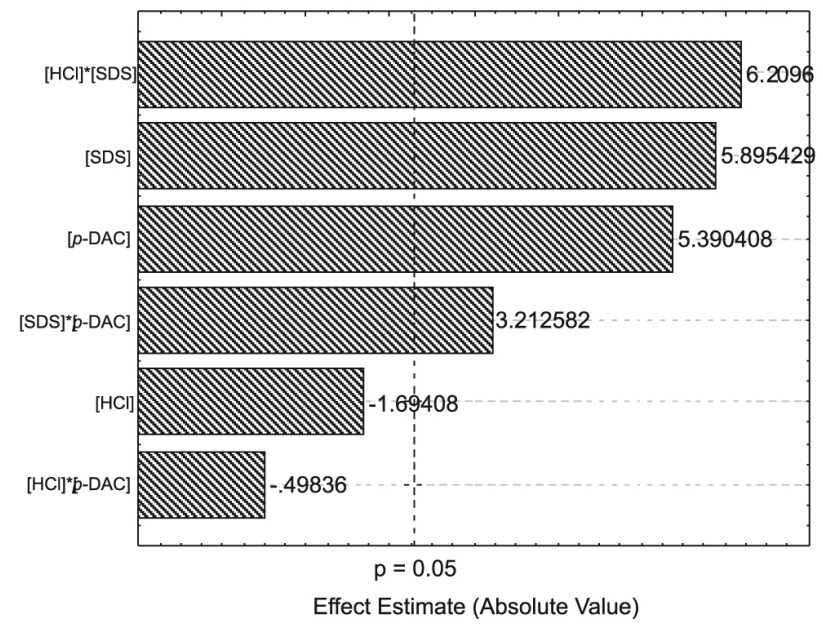

Figure 2. Pareto diagram for visualizing the effects of the chemical variables on the reflectance measurements $(\lambda=520 \mathrm{~nm})$ using a $2^{3}$ full factorial design

Pareto chart gives a graphical presentation for these effects and it allows looking at both the magnitude and the importance of an effect. In this Pareto chart, the bars (variables) that graphically overpass the significance line exert a statistically significant influence on the result. So, it can be seen in Figure 2, that SDS and $p$-DAC concentrations were the most significant factors, with a positive impact, indicating that the best results can be obtained when these factors are adjusted to a high level $(+1)$. The individual effect of the $\mathrm{HCl}$ concentration was not significant with a negative sign. Thus, the $\mathrm{HCl}$ concentration was set at $0.50 \mathrm{~mol} \mathrm{~L}^{-1}$ (the lowest concentration level studied). In addition, Pareto chart shows that the interactions effects was take account to ensure that all the combinations of factors levels were explored in the full factorial design. On the other hand, if each factor were only studied individually (univariated analysis), important effects might go undetected.

In the sequence, the best concentrations of $p$-DAC and SDS for the maximum reflectance signal were obtained using a central composite design. The Figure 3 represents the three-dimensional graph obtained from experimental data and fitted to the response surface.

The two factors were studied in five levels including four central points for statistical validity within the range -1.41 to +1.41 , which corresponds to the $p$-DAC with a concentration range of 0.40 to $1.00 \% \mathrm{~m} / \mathrm{v}$ and SDS with a concentration range of $2.0 \times 10^{-2}$ to $4.0 \times 10^{-2} \mathrm{~mol} \mathrm{~L}^{-1}$.

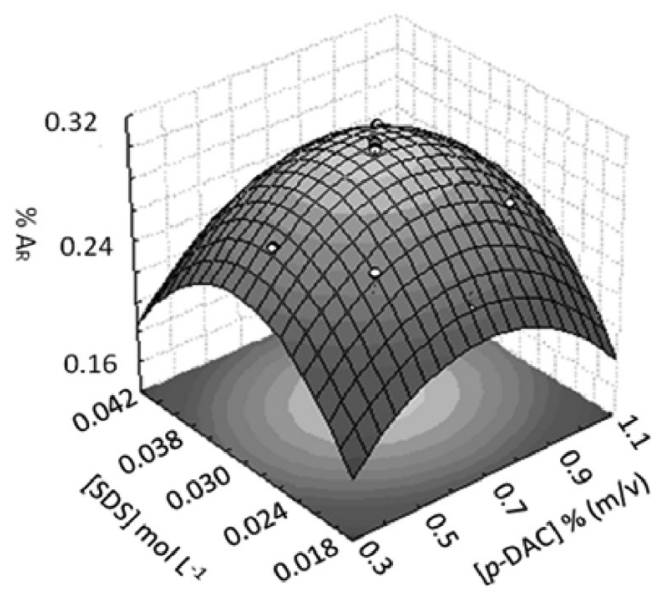

Figure 3. Three-dimensional plot of the optimized response surface, showing the reflectance as a function of the p-DAC and SDS concentrations
Analyzing the fitted surface, it is possible to identify that the points referring to the best conditions for the maximum reflectance signal were SDS $3.0 \times 10^{-2} \mathrm{~mol} \mathrm{~L}^{-1}$ and $p$-DAC $0.70 \%$ (w/v), which showed the higher absorbance values.

The quadratic regression model is given by Equation 1:

$Z=-0.27368+0.43294 x-0.326081 x^{2}+27.69875 y-464.59130 y^{2}$ $+1.09332 x y$

where $Z$ is the response factor corresponding to the $A_{\mathrm{R}}$ value. The factors $x$ and $y$ are the $p$-DAC and SDS concentrations, respectively. A statistically significant quadratic model, the $\mathrm{R}^{2}$ value, was greater than 0.89 implying that the data fitted the model well in relation to the reflectance response at a $95 \%$ confidence level. In the Table 2, are illustrated the values optimums of all the variables

Table 2. Optimum values of the all variables for the method

\begin{tabular}{lc}
\hline Variables & Optimum values \\
\hline$[\mathrm{HCl}] \mathrm{mol} \mathrm{L}^{-1}$ & 0.50 \\
{$[p-\mathrm{DAC}] \% \mathrm{~m} / \mathrm{v}$} & 0.70 \\
{$[\mathrm{SDS}] \mathrm{mol} \mathrm{L}^{-1}$} & $3.0 \times 10^{-2}$ \\
\hline
\end{tabular}

\section{Analytical data}

The developed analytical method was validated by evaluating the linear dynamic range, limit of detection (LOD), limit of quantification (LOQ), precision and accuracy as well as by applying the standard addition technique.

Under the optimized experimental conditions, the linear calibration curve was constructed from $1.21 \times 10^{-3}$ to $9.65 \times 10^{-3} \mathrm{~mol}$ $\mathrm{L}^{-1}$ (equivalent to 500-4000 $\mu \mathrm{g} \mathrm{mL} \mathrm{m}^{-1}$ ) of the ambroxol standard solutions. The least square treatment of calibration data $(n=5)$ yielded the regression equation: $A_{R}=-0.15048+0.4354 \times C$, where $A_{R}$ is the reflectance signal at $520 \mathrm{~nm}$ and $C=\log \left(10^{3}\right.$ [ambroxol] $/ \mathrm{mol}$ $\left.\mathrm{L}^{-1}\right)$. The correlation coefficient was 0.9997 , indicating the excellent linearity of the calibration curve.

The limit of detection (LOD) and the limit of quantification (LOQ) were calculated according to Skoog et.al. ${ }^{34}$ using the following expressions: $\mathrm{LOD}=3 \sigma / b$ and $\mathrm{LOQ}=10 \sigma / b$, where $\sigma$ is the standard deviation of twenty measurements of the blank, and $b$ is the slope of the analytical curves. The limit of detection and the limit of quantification were $3.50 \times 10^{-4} \mathrm{~mol} \mathrm{~L}^{-1}$ and $1.16 \times 10^{-3} \mathrm{~mol} \mathrm{~L}^{-1}(145$ and $481 \mu \mathrm{g} \mathrm{mL}^{-1}$ ), respectively.

The precision and accuracy were evaluated by comparing the results obtained from the analysis of pharmaceutical formulations by the proposed method with those obtained using a HPLC, described in the literature. ${ }^{7}$ The susceptibility of the developed analytical method to changes was tested to evaluate the ruggedness of the method. For this purpose the experimental designs were employed where the variables were tested.

The matrix interference can introduce systematic errors in analytical determinations. In order to investigate the presence of matrix effects in the proposed method, a recovery study was carried out. In this study, $1.20 \times 10^{-3}, 2.40 \times 10^{-3}, 3.60 \times 10^{-3}$ and $4.80 \times 10^{-3} \mathrm{~mol}$ $\mathrm{L}^{-1}$ of ambroxol reference solutions were added to three selected pre-analyzed pharmaceuticals (samples A, C, E). The recoveries obtained by the standard-addition method ranged from 97.2 to $102.4 \%$, indicating the absence of any significant matrix effects on the proposed method.

The effects of the common excipients present in commercial pharmaceutical formulations, such as benzoic acid, sorbitol, citric 
Table 3. Determination of ambroxol in pharmaceutical formulations (syrups)

\begin{tabular}{|c|c|c|c|c|c|}
\hline \multirow{2}{*}{ Sample } & Label & Proposed method & Comparative method $^{7}$ & $t$ value & $F$ value \\
\hline & value $^{\mathrm{a}}$ & Found ${ }^{b}$ & Found ${ }^{b}$ & $(2.78)^{\mathrm{c}}$ & $(19.00)^{c}$ \\
\hline A & 30 & $29.3 \pm 0.8$ & $30.2 \pm 0.6$ & 1.51 & 1.78 \\
\hline B & 30 & $29.9 \pm 1.1$ & $28.8 \pm 0.7$ & 1.47 & 2.47 \\
\hline $\mathrm{C}$ & 30 & $31.1 \pm 1.3$ & $29.1 \pm 0.6$ & 2.38 & 5.06 \\
\hline D & 30 & $29.4 \pm 1.2$ & $29.8 \pm 0.7$ & 0.44 & 4.59 \\
\hline E & 15 & $14.8 \pm 1.0$ & $15.4 \pm 0.4$ & 0.93 & 6.01 \\
\hline
\end{tabular}

a. Content: $\mathrm{mg} / 5 \mathrm{~mL}$; b. Average \pm standard deviation (SD) of three independent analysis; c. Theoretical values of $t$ and $F$ at $95 \%$ confidence level.

acid, hydroxyethylcellulose, sodium citrate, sucrose, propylene glycol, tartaric acid, glycerol, methylparaben and propylparaben were carefully evaluated. The effects were considered to be interference when the signal showed an error of more than $3 \%$ in determination of the drug.

\section{Analytical applications}

The applicability of the proposed method for the determination of ambroxol in pharmaceutical preparations (syrups) was examined by analyzing marketed products. The results were statistically ${ }^{35}$ compared with those obtained by the comparative HPLC method ${ }^{7}$ and are summarized in Table 3. In all cases, the calculated $t$ and $F$ values are less than the theoretical ones at $95 \%$ confidence level, indicating there is no significant difference between either method regarding to precision and the accuracy in the determination of ambroxol in pharmaceutical formulations (syrups).

\section{CONCLUSION}

The results presented provide evidence that the method based on the reflectometric technique can be an advantageous alternative for determination of ambroxol hydrochloride in syrups. The method is fast, inexpensive and has been applied with satisfactory precision and accuracy to the determination of ambroxol hydrochloride in pharmaceutical expectorant preparations.

\section{ACKNOWLEDGMENTS}

We would like to thank CAPES, FAPESP, CNPq and FUNDUNESP foundations (Brazil) for financial support.

\section{REFERENCES}

1. Felix, F. S.; Brett, C. M. A.; Angnes, L.; Talanta 2008, 76, 128.

2. Nobilis, M.; Pastera, J.; Svoboda,D.; Kvetina, J.; J. Chromatogr. 1992, $581,251$.

3. Indrayanto, G.; Handajani, R.; J. Pharm. Biomed. Anal. 1993, 11, 781.

4. Musumarra, G.; Scarlata, G.; Cirma, G.; Romano, G.; Palazzo, S.; Clementi, S.; Giulietti, G.; J. Chromatogr. 1985, 350, 151.

5. Musumarra, G.; Scarlata, G.; Romano, G.; Cappelo, G.; Clementi, S.; Giulietti, G.; J. Anal. Toxicol. 1987, 11, 154.

6. Kim, H.; Yoo, J.; Han, S. B.; Lee, H. J.; Lee, K. R.; J. Pharm. Biomed. Anal. 2003, 32, 209.

7. Dincer, Z.; Basan, H.; Göger, N. G.; J. Pharm. Biomed. Anal. 2003, 31, 867.

8. Heinanen, M.; Barbas, C.; J. Pharm. Biomed. Anal. 2001, 24, 1005.

9. Bazylak, G.; Nagels, L. J.; J. Pharm. Biomed. Anal. 2003, 32, 887.
10. Koundourellis, J. E.; Malliou, E. T.; Broussali, T.; J. Pharm. Biomed. Anal. 2000, 23, 469.

11. Ruiz, T. P.; Lozano, C. M.; Sanz, A.; Miguel, M. T. S.; Talanta 1996, 43, 1029 .

12. Ghani, N. T. A.; Hussein, S. H.; Il Farmaco 2003, 58, 581

13. Ruiz, T. P.; Lozano, C. M.; Sanz, A.; Bravo E.; J. Chromatogr., B: Biomed. Sci. Appl. 1997, 692, 199.

14. Pospíšilová, M.; Polášek, M.; Jokl, V.; J. Pharm. Biomed. Anal. 2001, $24,421$.

15. Matias, F. A. A.; Vila, M. M. D. C.; Tubino, M.; J. Braz. Chem. Soc. 2004, 15, 327.

16. Gotardo, M. A.; Gigante, A. C.; Pezza, L.; Pezza, H. R.; Talanta 2004, 64,361 .

17. Matias, F. A. A.; Vila, M. M. D. C.; Tubino, M.; Sens. Actuators B 2003, 88,60 .

18. Ghauch, A.; Turnar, C.; Fachinger, C.; Rima, J.; Charef, A.; Suptil, J.; Bouyer, M. M.; Chemosphere 2000, 40, 1327.

19. Ghauch, A.; Rima, J.; Charef, A.; Suptil, J.; Fachinger, C.; Bouyer, M. M.; Talanta 1999, 48, 385.

20. Malcik, N.; Caglar, P.; Narayanaswamy, R.; Quim. Anal. 2000, 19, 94.

21. Zareh, M. K.; Mansourian, M.; Ravaee, F.; Anal. Chim. Acta 2002, 471, 97.

22. Gotardo, M. A.; Pezza, L.; Pezza, H. R.; Eclet. Quim. 2005, 30, 17.

23. Gotardo, M. A.; Tognolli, J. O.; Pezza, H. R.; Pezza, L.; Spectrochim. Acta Part A 2008, 69, 1103.

24. Tubino, M.; Souza, R. L.; Talanta 2006, 68, 776.

25. Montgomery, D. C.; Myers, R. H.; Response Surface Methodology: Process and Product Optimization Using Designed Experiments, $2^{\text {nd }}$ ed., Wiley: New York, 2002.

26. Tubino, M.; Rossi, A. V.; Magalhães, M. E. A.; Anal. Lett. 1997, 30, 271.

27. Zawilla, N. H.; Mohammad, A. A.; Kousy, N. M. E.; Aly, S. M. E. M.; J. Pharm. Biomed. Anal. 2002, 27, 243.

28. El-Sherif, A. A.; Walash, M. I.; El-Tarras, M. F.; Osman, A. O.; Anal. Lett. 1997, 30, 1881.

29. Esteve-Romero, J. S.; Simó-Alfonso, E. F.; Garcia-Alvarez-Coque, M. C.; Ramis-Ramos, G.; Trends Anal. Chem. 1995, 14, 29.

30. Doronin, S. Y.; Chernova, R. K.; Gusakova, N. N.; Russ. J. Gen. Chem. 2005, 75, 261.

31. Yatziirsky, A. K.; Yatzimirsky, N. T.; Krinova, S.; Anal. Chem. 1994, 66, 2232.

32. Esteve-Romero, J. S.; Pons, L. M.; Garcia-Alvarez-Coque, M. C.; Ramis-Ramos, G.; Anal. Lett. 1994, 27, 1557.

33. Wendlant, W. W.; Hecht, H. G.; Reflectance Spectroscopy, Interscience Publishiers: New York, 1996.

34. Skoog, D. A.; Holler, F. J.; Nieman, T. A.; Principles of Instrumental Analysis, $5^{\text {th }}$ ed., Harcourt Brace Company: Philadelphia, 1998.

35. Miller, J. C.; Miller, J. N.; Statistics for Analytical Chemistry, $2^{\text {nd }}$ ed., Ellis Horwood Limited: London, 1992. 